\title{
Dopamine devils
}

\section{Demônios dopaminérgicos}

Pedro BARBOSA ${ }^{1,2}$, Andrew John LEES ${ }^{1}$

\author{
${ }^{1}$ University College London, \\ Institute of Neurology, \\ Department of Clinical Movement \\ Disorder and Neuroscience, \\ Reta Lila Weston Institute of \\ Neurological Studies, London, UK \\ Universidade de São Paulo, São \\ Paulo SP, Brazil. \\ PB (10 http://orcid.org/0000-0001- \\ 7220-1563 \\ AJL (10 https://orcid.org/0000- \\ 0002-2476-4385 \\ Conflicts of Interest: There is no \\ conflict of interest to declare. \\ Correspondence: Pedro Barbosa; \\ Email:pmbarbosa@me.com. \\ Authors' contributions: PB, AJL \\ contributed equally to writing the \\ manuscript. AJL has contributed \\ with critical revision and final \\ approval of the manuscript. \\ Received on July 20, 2021; \\ Accepted on July $21,2021$.
}

$\mathrm{T}$ he first description of dopamine dysregulation syndrome (Lees Syndrome) ${ }^{1}$ was published 21 years ago ${ }^{2}$. This led to a resurgence of interest in the role of dopamine in mediating addictive behaviour in Parkinson's disease (PD).

Pathological impulsivity caused by dopaminergic drugs can be divided into two broad and closely related groups: the commoner impulse control disorders including pathological gambling, hypersexuality and binge eating; and punding and dopamine dysregulation syndrome. Both groups of behavioural disorders may be seen in the same patient, but impulse control disorders, especially pathological gambling, are more commonly seen with dopamine agonists and dopamine dysregulation syndrome and punding with l-dopa.

Considerable progress has been made in our understanding of impulse control disorders. About one in six patients with Parkinson's disease are affected, and the main risk factors are now known to be male sex, a premorbid history of depression and younger age at PD onset ${ }^{3,4}$. Neuropsychological studies have shown that these vulnerable individuals have a preference for immediate rewards ('take the money and run') and tend to jump to conclusions ${ }^{5}$. Functional neuroimaging studies have demonstrated excessive dopaminergic release in the ventral striatum similar to that seen in cocaine addiction and a correlation with wanting medication rather than liking $\mathrm{it}^{6,7}$. A recent clinico-pathological study has revealed that individuals who had PD and ICBs in life have less alpha-synuclein pathology in the nucleus accumbens, supporting the notion that ICBs could result from over stimulation of a relatively preserved ventral striatum by dopaminergic medication ${ }^{8}$.

Treatment remains challenging. Data from observational studies show that a slow reduction of dopaminergic therapy starting with a tailing off of dopamine agonists (DA) is the single most effective approach ${ }^{4,9}$. Previous authors have also shown that remission can sometimes occur naturally ${ }^{10}$, although longer term studies suggest that relapse is common ${ }^{11}$. A clinical trial with the opioid antagonist naltrexone failed to achieve its primary outcome ${ }^{12}$. The devastating impact that ICBs can have on the life of patients already disabled with PD, and the fact that as many as half of the individuals remain symptomatic over many years despite medication reduction, highlights the need for better treatments. Randomised clinical trials using 'off label' drugs are increasingly difficult to perform, and the pharmaceutical industry has so far shown little interest in developing new drugs for impulse control disorders or even serious social problems like CNS stimulant addiction which closely resembles dopamine dysregulation in PD.

In this edition of Arquivos de Neuropsiquiatria, Rodríguez-Violante and co-authors have gathered information from PD patients who were seen at baseline and then followed regularly in a movement disorders clinic in Mexico ${ }^{13}$. The patients were assessed using the Questionnaire for Impulsive-Compulsive Disorders in Parkinson's Disease - Rating Scale (QUIP-RS) ${ }^{14}$. Clinical judgement rather than blanket reduction of medication was used to manage those patients suspected on clinical grounds and on the QUIP-RS to have impulse control behaviours.

The authors observed a high overall remission rate of $80 \%$, which is in line with the literature ${ }^{10,15}$. All the patients in the study with impulse control disorders and related behaviours whose treatment was left unchanged and monitored remitted spontaneously. Furthermore, a small group of individuals whose dopaminergic treatment was increased also showed a $60 \%$ remission rate. The magnitude of reduction of the QUIP-RS scores in those individuals who continued on the same or higher dosage of DA is remarkable and requires explanation.

The small numbers of patients in each treatment group and the sole use of the QUIP-RS to diagnose ICBs are methodological limitations. The QUIP-RS is a screening instrument recognised to be associated with a high rate of false positives. Two main issues could have resulted as a 
consequence of the sole use of the QUIP-RS to diagnose ICBs. Firstly, it is possible that many asymptomatic patients were classified as having a behavioural abnormality, as suggested by the high number of individuals with punding in the study cohort. Furthemore, the overall QUIP-RS scores suggest that most of the patients who scored above cut-off values had mild ICBs, some possibly of no clinical relevance as suggested by the treating physician's decision to not alter the dopaminergic treatment. We have no explanation for the reduction in the QUIP-RS scores in patients who remained on the same or even higher dosage of DA.

This paper by Rodríguez-Violante and co-authors is a salutary reminder of the pressing need for more data on the course of impulsive compulsive behaviours in $\mathrm{PD}$ and also raises issues about the validity of the QUIP-RS in diagnosing and measuring ICBs severity. Could repeated testing have affected the QUIP-RS results in the study? Are these individuals still exhibiting tolerated ICBs? Did loss of insight contribute to the lower scores at follow-up? These questions can be addressed by the authors by longer follow up.

Mild ICBs may be desired by many patients and tolerated by the patients' families, and there are also important cultural differences in relation to acceptance. However, for the time being it would be our recommendation that for any patient on dopamine agonists who has pathological gambling, the drug should be tailed off slowly and, if necessary, replaced by an increased dose of l-dopa to minimize the risk of dopamine withdrawal apathy, and in Lees' syndrome and punding continuous dopamine delivery with either apomorphine or enteral dopa should be considered.

\section{REFERENCES}

1. Becker N, Munhoz RP, Teive HAG. Lees' syndrome: a case series. Arq Neuropsiquiatr. 2011 Oct;69(5):756-9. https://doi.org/10.1590/ S0004-282X2011000600006

2. Giovannoni G, O'Sullivan JD, Turner K, Manson AJ, Lees AJL. Hedonistic homeostatic dysregulation in patients with Parkinson's disease on dopamine replacement therapies. J Neurol Neurosurg Psychiatry. 2000 Apr;68(4):423-8. https://doi.org/10.1136/ jnnp.68.4.423

3. Weintraub D, Koester J, Potenza MN, Siderowf AD, Stacy M, Voon V, et al. Impulse control disorders in Parkinson disease: a cross-sectional study of 309 patients. Arch Neurol. 2010 May;67(5):589-95. https:// doi.org/10.1001/archneurol.2010.65

4. Averbeck B, O'Sullivan SS, Djamshidian A. Impulsive and compulsive behaviours in Parkinson's disease. Annu Rev Clin Psychol. 2014;10:553-80. https://doi.org/10.1146/annurevclinpsy-032813-153705

5. Housden CR, O'Sullivan SS, Joyce EM, Lees AJ, Roiser JP. Intact reward learning but elevated delay discounting in Parkinson's disease patients with impulsive-compulsive spectrum behaviors. Neuropsychopharmacology. 2010 Oct;35(11):2155-64. https://doi. org/10.1038/npp. 2010.84

6. Evans AH, Pavese N, Lawrence AD, Tai YF, Appel S, Doder M, et al. Compulsive drug use linked to sensitized ventral striatal dopamine transmission. Ann Neurol. 2006 May;59(5):852-8. https://doi. org/10.1002/ana.20822

7. O'Sullivan SS, Wu K, Politis M, Lawrence AD, Evans AH, Bose SK, et al. Cue-induced striatal dopamine release in Parkinson's disease-associated impulsive-compulsive behaviours. Brain. 2011 Apr;134(4):969-78. https://doi.org/10.1093/brain/awr003

8. Barbosa P, Hapuarachchi B, Djamshidian A, Strand K, Lees AJ, Silva $R$, et al. Lower nucleus accumbens $\alpha$-synuclein load and D3 receptor levels in Parkinson's disease with impulsive compulsive behaviours. Brain. 2019 Nov 1;142(11):3580-91. https://doi.org/10.1093/brain/awz298

9. Bastiaens J, Dorfman BJ, Christos PJ, Nirenberg MJ. Prospective cohort study of impulse control disorders in Parkinson's disease. Mov Disord. 2013 Mar;28(3):327-33. https://doi.org/10.1002/mds.25291

10. Corvol J-C, Artaud F, Cormier-Dequaire F, Rascol O, Durif F, Derkinderen $\mathrm{P}$, et al. Longitudinal analysis of impulse control disorders in Parkinson disease. Neurology. 2018 Jul 17;91(3):e189201. https://doi.org/10.1212/WNL.0000000000005816

11. Barbosa PM, Djamshidian A, O'Sullivan SS, Pablo-Fernandez E, Korlipara P, Morris HR, et al. The long-term outcome of impulsive compulsive behaviours in Parkinson's disease. J Neurol Neurosurg Psychiatry. 2019 Nov;90(11):1288-9. https://doi.org/10.1136/jnnp2018-319891

12. Papay K, Xie SX, Stern M, Hurting H, Siderowf A, Duda JE, et al. Naltrexone for impulse control disorders in Parkinson disease: a placebo-controlled study. Neurology. 2014 Aug 26;83(9):826-33. https://doi.org/10.1212/WNL.0000000000000729

13. Rodríguez-Violante M, Ríos-Solís Y, Esquivel-Zapata O, et al. Assessment of therapeutic strategies for the management of impulse control disorder in Parkinson's disease. Arq Neurpsiquiatr. 2021;79(11):989-94. https://doi.org/10.1590/0004-282XANP-2020-0507

14. Weintraub D, Mamikonyan E, Papay K, Shea JA, Xie SX, Siderowf A. Questionnaire for impulsive-compulsive disorders in Parkinson's disease-Rating Scale. Mov Disord. 2012 Feb;27(2):242-7. https://doi. org/10.1002/mds.24023

15. Mamikonyan E, Siderowf AD, Duda JE, Potenza MC, Horn S, Stern MB, et al. Long-term follow-up of impulse control disorders in Parkinson's disease. Mov Disord. 2008 Jan;23(1):75-80. https://doi.org/10.1002/ mds. 21770 